ORIGINAL ARTICLE

ARTIGO ORIGINAL

\section{Comparative analysis between prevention and treatment costs for gestational diabetes mellitus in primary and tertiary health care in a city in Southern Brazil}

\author{
Análise comparativa entre os custos de prevenção e tratamento \\ do diabetes mellitus gestacional na assistência à saúde \\ primária e terciária em uma cidade do Sul do Brasil
}

Ricardo Reichenbach1, Yasmin Cristina Ricardo dos Reis², Maria Carolina Rosa Gullo ${ }^{3}$, Jose Mauro Madi', Rosa Maria Rahmi ${ }^{5}$

DOI: 10.21115/JBES.v13.n1.p21-30

\section{Keywords}

diabetes mellitus gestational, cost allocation, primary health care, secondary care

\section{Palavras-chave:}

diabetes mellitus gestacional, alocação de custos, atenção primária à saúde, atenção secundária

\section{RESUMO}

\begin{abstract}
Objective: The present study's purpose is to evaluate the economic context in which the Brazilian public health system, the only universal public health system with more than 200 million users, stands out. This evaluation will be made through the lens of the execution of gestational health care services in a city of approximately 500 thousand inhabitants in southern Brazil. The care costs of patients with gestational diabetes mellitus (GDM) will be compared to those of patients without GDM, analyzing the different economic valuation methods. And lastly, there was an intent to explore the generated costs in the context of economic valuation applied to health to comprehend better the complexity of the union of the financial and health areas to optimize the services offered. Methods: For the economic context in health, an analysis of health investments was performed through the Transparency Portal. The costs involved in preventing GDM were raised by the Sistema Único de Saúde (SUS) table of procedures performed ordinarily in low-risk pregnancies. The expenses involved in DMG patients were increased at the High-Risk Pregnancy and Fetal Medicine Clinic of DMG patients. Results: Preventing GDM is more cost-effective, cost-minimizing, and cost-useful than treating patients diagnosed with GDM. Conclusion: The result is an extremely interesting costopportunity, given the economic context in which it is presented.
\end{abstract}

Objetivo: $O$ presente estudo tem como objetivo avaliar o contexto econômico em que se encontra o sistema público de saúde brasileiro, único sistema público universal de saúde com mais de 200 milhões de usuários. Essa avaliação será feita sob a ótica da execução de serviços de saúde gestacional em um município de aproximadamente 500 mil habitantes no Sul do Brasil. Os custos assistenciais de pacientes com diabetes mellitus gestacional (DMG) serão comparados aos de pacientes sem DMG, analisando os diferentes métodos de valoração econômica. Também serão analisados os custos gerados no contexto da valoração econômica aplicada à saúde para uma melhor compreensão da complexidade da união das áreas econômica e da saúde com o objetivo de otimizar os serviços oferecidos. Métodos: Para a contextualização econômica em saúde, foi feita a análise dos investimentos em saúde pelo Portal da Transparência. Os custos envolvidos na prevenção da DMG foram levantados pela tabela de procedimentos realizados ordinariamente em gestações de

Received on: 02/27/2021. Approved for publication on: 04/19/2021

1. Medicine Undergraduate Course from the Universidade de Caxias do Sul, Caxias do Sul, RS, Brazil.

2. Bachelor of Economics by the Universidade de Caxias do Sul, Caxias do Sul, RS, Brazil.

3. PhD in Economics by the Universidade Federal do Rio Grande do Sul, Porto Alegre, RS, Brazil.

4. PhD in Obstetrics by the Federal University of Rio de Janeiro, Rio de Janeiro, RJ, Brazil.

5. PhD in Sciences by the University of São Paulo, São Paulo, SP, Brazil.

Institution where study was done: Department of Medicine and Economics of the University of Caxias do Sul.

Conflict of interests: No sources of financing and no conflict of interest.

Congress: This job had no previous presentation.

Corresponding author: Ricardo Reichenbach. Rua Francisco Getúlio Vargas, 1.130, Caxias do Sul, RS, Brazil. CEP: 95070-560.

Telephone: +55 (51) 99895-4868. E-mail: rreichenbach@ucs.br / ricardoreichenbach@hotmail.com 
baixo risco do Sistema Único de Saúde (SUS). Os custos envolvidos em pacientes com DMG foram levantados no Ambulatório de Gestação de Alto Risco e Medicina Fetal de pacientes com DMG. Resultados: Prevenir o DMG apresenta maiores custo-benefício, custo-efetividade, custo-minimização e custo-utilidade em comparação com o tratamento das pacientes com o diagnóstico de DMG. Conclusão: $\bigcirc$ resultado é um custo-oportunidade extremamente interessante, dado o contexto econômico em que se apresenta.

\section{Introduction}

Cost management in health is one of the topics that connect the areas of Health and Economy. Although with distinct study fields, both areas complement each other with different views regarding resource management. Under the lenses of Economy cost management, it is observed under a macro and microeconomic aspect, in short, and long terms, analyzing the sources of cost and the ends in obtaining results. In turn, Medicine explores costs under a social perspective, justifying the usage of resources to improve patients' quality of life.

According to the desired results the researcher aims for, within the scope of research carried out in the area regarding costs, methods capable of making a complete analysis of these costs emerge. These methods have the goal of promoting an efficient intervention to provide a better allocation of resources. Many of them account for cost evaluation in health, such as Cost-Benefit, Cost Effectiveness, Cost Minimization and Cost-Utility.

In this context, in Brazil, from 2006 to 2016, according to the Ministry of Health (Brazil, Ministry of Health, 2012), there was a $60 \%$ increase in diabetes diagnosis. A study published in March of 2018 by the British University King's College in partnership with the German University of Gottingen (Bommer et al., 2018) says that costs with diabetes will double by 2030 in Brazil, it can reach up to US\$ 97 billion, in more conservative estimates, or even up to US\$ 123 billion (R\$ 406 billion), in a worst-case scenario.

Gestational diabetes mellitus (GDM) is a metabolic disorder in which the woman's organism shows high levels of glucose throughout the gestational period. The prevalence is also increasing, for it presents the same risk factors related to the development of type 2 Mellitus diabetes related to diet and lifestyle. The GDM creates important risks to the mother's health in short and long terms, to the fetal development, children, and in the adult stage, whose mothers had GMD.

The current prevalence of GDM varies from 1\% to 37\% from pregnant women worldwide, with an average of 16.2\% (Brazil, 2017). The GDM estimate frequency in Brazil is conflicting; however, it is estimated that the prevalence of GDM on Sistema Único de Saúde (SUS) [Brazilian National Health System] is 18\% (Trujillo et al., 2016).

The present study intends to evaluate the economic context that the health office not only the city of Caxias do Sul - RS has, but also the federal, the state, and the municipal, to analyze the funding percentile established by law and the health office's real revenue. In addition, it intends to analyze different economic valuation methods in the prevented costs when a pregnant woman does not contract GMD, comparing to the treatment costs from this disease in an ambulatory from a tertiary health care hospital from southern Brazil to the ordinary expenses of a patient's care that did not develop GMD in a Basic Health Unit (BHU)/Unidade Básica de Saúde (UBS) in the same city. Lastly, it intends to analyze the results generated in the context of economic valuation applied to health for a better understanding of the complexity to optimize the service.

\section{Methods}

This article has been approved by the Ethics and Research Committee registered under the protocol 35/2018.

This research's methodology was characterized by data analysis, using the theoretical method of cost theory and the quantitative method on health investments from Brazil, from the State of Rio Grande do Sul and the city of Caxias do Sul. Initially, the cost theory was searched in literature, its variations, and its applicability to the Health area. For the investment analysis to be performed in the government spheres studied, a survey was carried out on Government Spending online report (Portal da Transparência e Acesso à Informação-Transparency and Access to Information Portal). For performing comparative analysis, research and analysis of costs involved in the GMD pathological prevention and costs involved after the disease contraction and comparing the results were achieved.

Some research was carried out to evaluate costs involved in GMD women's prenatal care and delivery at the Ambulatório de Atendimento à Gestante de Alto Risco e Medicina Fetal do Hospital Geral de Caxias do Sul (AAGAR/HG)/HighRisk Pregnancy Care and Fetal Medicine Outpatient Clinic of Hospital Geral in the city of Caxias do Sul, from now on, called HG. With the support and collaboration of the Billing, Purchase, Medical, and Statistical Filing sectors and AAGAR/ HG sector, throughout multiple visits to the Hospital from August 2018 to May 2019. Data and medical examination records were collected through the medical records and the electronic system access.

Cost analyses involved in non-GMD women's prenatal care and delivery, or other high-risk pregnancy-related pathology, were performed based on data and information collected from Caxias do Sul City Hall and protocols from the 
Ministry of Health that standardize treatment care for this population. The values of the procedures evaluated were collected in September 2018 from the Brazilian National Health System's (SUS) remuneration table.

Data collected from the Hospital Geral (HG) medical records were used in the preparation of the information collection worksheet, contemplating, among other information, family and personal history, obstetric history, reasons of medical consultation, number of prenatal consultations, amount and description of medical tests performed, hospitalization, delivery, and hospital discharge dates.

Medical record numbers were sorted in ascending order, from lowest to highest, and the selection was based on the hospital discharge date during the year 2018. Four hundred ninety-three medical records have been observed to identify primary services provided to women with GMD under care by AAGAR/HG from HG in 2018. For accessing this information, the research project must be submitted to both evaluation and approval of the Ethics Committee and involved sectors from Hospital Geral, per Resolution no 196/96. The primary hospital services utilized were evaluated. The general values from all described services from the medical records were added and then divided by their number, resulting in the arithmetic mean of GMD patient's costs. Microsoft Excel was used to extract data and perform calculations.

For the percentile analysis of the legal health budget that the Municipal Health Office of Caxias do Sul had available, evaluation of the Brazilian legislation was necessary. For the monetary analysis of the current budget that the Municipal Health Office of Caxias do Sul had in the year 2018, a search was carried out in the Transparency Portal and the daily official reports by the municipal press department.

\section{Results}

\section{Health investments}

In Brazil, according to the Ministry of Health, the provision of health care and treatment is the responsibility of the Brazilian National Health System (SUS), which is one of the largest and most complex systems in the world. The Federal Constitution instituted the system in 1988, article 196. With its creation "[...] the thorough attention to health, and not only to support care, has become a right to all Brazilians, since birth, and throughout their whole life, with focus on health and quality of life, aiming for prevention and the promotion of health" (Brazil, Ministry of Health, 2019a).

The Law no 8,080, from 1990 (Brazil, 1990), has the objective of regulating the system, and guarantee its functioning. It establishes the government's obligation to guarantee the population's access to the services provided. SUS provides services in all national territories, stipulated by law it is mandatory and a responsibility of the government to maintain and guarantee access, also to establish the funding made in municipal, state, and federal levels.

$\S 1$ - The State's duty to guarantee health consists of formulating and executing economic and social policies to reduce the risks of diseases and other illnesses and establish conditions that ensure universal and equal access to actions and services for health promotion, protection, and recovery. Presidency of the Republic (Brazil, 1990).

According to their tax collection, to guarantee investments made in the area, the Brazilian legislation establishes a minimum value that the federal union, states, and cities must invest in the health sector. The Complementary Law no141 from 2012 (Brazil, Presidency of the Republic, 2012) discusses the percentage that the states, cities, and the Federal District must apply in health.

Art. 6. The States and the Federal District will invest, annually, in public health actions and services, at least, 12\% (twelve percent) of taxes collection referred to in art. 155 and the resources referred to in art. 157, item "a" of item I and item Il of the caput of art. 159, all from the Federal Constitution, less the installments that are transferred to the respective Municipalities.

Art. 7. The Municipalities and the Federal District will invest annually in actions and public health services, at least $15 \%$ (fifteen percent) of taxes collection referred to in art. 156 and the resources referred to in art. 158 and item "b" of item I of the caput and $\S 3$ of art. 159, all of the Federal Constitution. Presidency of the Republic (Brazil, Presidency of the Republic, 2012b).

It should be noted that there is no minimum stipulation for which tax collection percentile the Union must be categorized. It is, however, demanded by the complementary law No. 141 from 2012 (Brazil, Presidency of the Republic, 2012b) that the Union must invest in health, at least, the value invested last year plus the nominal variation of the Gross Domestic Product (GDP).

In 2018, according to news published by the press office of the Municipal Health Office (2019), the city exceeded 254 million investments in health during the year; R\$ $254,361,095.01$ was invested, representing $27.3 \%$ of the city's total revenues in the year. This amount was $17.2 \%$ higher than that invested in the previous year, 2017, and 13.4\% higher than that invested in 2016. Table 1 below shows the amounts invested in health by Caxias do Sul, from 2015 to 2018.

According to the municipal health secretary in office during 2018, Júlio César Freitas (Caxias do Sul, 2019), "as the resources coming from the Union and the State are out-ofdate, the City needs to supplement this amount more and more". The table above shows that from 2015 to 2018, the city funding was more significant than required by law in all years. 
Table 1. Values invested in health by the city of Caxias do Sul, from 2015 to 2018

\begin{tabular}{lccc}
\hline Year & Total of health expenditures & $\begin{array}{c}\text { Expenditures computed for purposes of } \\
\text { calculating the minimum percentage }\end{array}$ & Percentages of investment in health \\
\hline 2015 & $R \$ 381,934,928.76$ & $R \$ 220,337,942.96$ & $26.21 \%$ \\
\hline 2016 & $R \$ 403,827,103.01$ & $R \$ 224,211,585.33$ & $25.02 \%$ \\
\hline 2017 & $R \$ 416,265,638.11$ & $R \$ 216,869,473.86$ & $24.71 \%$ \\
\hline 2018 & $R \$ 458,668,522.58$ & $R \$ 254,361,095.01$ & $27.34 \%$ \\
\hline
\end{tabular}

Source: Prepared by the authors based on data obtained by the Ouvidoria de Acesso à Informação.

Table 2. Percentages applied (paid nominal) in Health in relation to NRTT R\$ million between the years 2015 and 2018

\begin{tabular}{llccc}
\hline Specification & $\mathbf{2 0 1 5}$ & $\mathbf{2 0 1 6}$ & $\mathbf{2 0 1 7}$ & $\mathbf{2 0 1 8}$ \\
\hline Total applied in Health & 3,219 & 3,559 & 3,787 & 4,090 \\
\hline Net Revenue Taxes and Transfers - NRTT & 26,256 & 29,176 & 30,842 & 33,634 \\
\hline Percentage of Health on NRTT & $12.2 \%$ & $12.1 \%$ & $12.2 \%$ & $12.2 \%$ \\
\hline
\end{tabular}

Source: Prepared by authors based on data from the "Message to the Legislative Assembly 2019" (Rio Grande do Sul, 2019).

Like what happened in the city of Caxias do Sul, which significantly exceeded the mandatory percentage of funds, the state of Rio Grande do Sul also exceeded the funds required by Law (Caxias do Sul, 2019) - 12\% of Net Revenue Taxes and Transfers -, but very less expressive as can be seen in Table 2 (Rio Grande do Sul, 2019).

\section{Gestational costs}

The treatment for GDM involves weekly monitoring of the patient through blood glucose tests, furthermore, requiring a prepared medical staff, nurses, and nutritionists.

GMD prevention is (or should be) for all women undergoing prenatal care, it is made through diet orientation given by the doctor in charge of the UBS, also encouraging for physical activities, fasting glucose test in the first trimester, and oral glucose tolerance test in the second trimester to determine blood glucose levels.

The HG does not accept low-risk pregnant women for consultation and prenatal care, only for delivery. The monitoring of these pregnancies occurs through periodic consultations in their UBS, knowingly that they generate lower costs since large structures and specialized teams are not required.

Table 3 was completed using data from different sources. Thus, it was observed that consultations in UBS were not included in the SUS remuneration table, since in no circumstance SUS outsources such service, the value was obtained through consultation in the Portal da Transparência e Acesso à Informação (Transparency and Access to Information Portal) (Brazil, Federal Government, 2018), each medical consultation in September 2013 had cost R\$ 6.30 to SUS. Those women, at minimum, must attend six prenatal consultations adding at the end of the pregnancy period the value of $R \$ 37.80$.
Table 3. Gestational costs with no complications during pregnancy

\begin{tabular}{lc}
\hline 6 consultations at the UBS* & $R \$ 37.80$ \\
\hline 1 ultrasound** & $\mathrm{R} \$ 24.20$ \\
\hline Delivery & $\mathrm{R} \$ 443.40$ \\
\hline Admission in the Obstetric Center & $\mathrm{R} \$ 16.00$ \\
\hline Laboratory Costs & $\mathrm{R} \$ 283.24$ \\
\hline Maternity hospitalization & $\mathrm{R} \$ 56.12$ \\
\hline Total & $\mathbf{R} \mathbf{8 6 0 . 7 6}$ \\
\hline
\end{tabular}

Source: Prepared by authors based on values of the SUS reference table of September 2018 (Brazil, Ministry of Health, 2019b) and additional information from the HG Billing sector.

There is a possibility that low-risk pregnant women must undergo ultrasound tests, which are performed, usually between the first and second quarter. This value was informed by the HG's billing sector, where patients referred by the UBS can have their ultrasound tests performed and check if there are any fetal malformation and the fetal sex. This imaging test costs $R \$ 24.20$ to SUS.

It is recommended that these patients have natural delivery performed. In some cases, however, it is not possible due to the fetal position or the mother's desire to go through a cesarean section, for example. But in the vast majority, it is natural delivery, costing $R \$ 443.40$ to SUS.

Admission in the Obstetric Center is accounted in daily rates, where women stay for a couple of hours until the delivery - labor does not last longer than 18 hours, but a full daily fee is charged for each patient in labor admitted in the $\mathrm{OC}$, the value was informed by the HG's Billing Sector, and R\$ 16.00 is paid by SUS. The costs of the laboratory tests recommended by the Ministry of Health (Brazil, Ministry of 
Table 4. Laboratory test values according to the Ministry of Health (Brazil, Ministry of Health, 2018) for healthy pregnancies

\begin{tabular}{|c|c|}
\hline \multicolumn{2}{|l|}{ First Trimester Laboratory Tests } \\
\hline Urine type-1 & $R \$ 3.70$ \\
\hline Urine Culture & $\mathrm{R} \$ 5.62$ \\
\hline Hemogram - CBC & $\mathrm{R} \$ 4.11$ \\
\hline Blood Type & $\mathrm{R} \$ 15.00$ \\
\hline Rhesus Test & $R \$ 10.65$ \\
\hline Syphilis - VDRL & $\mathrm{R} \$ 2.83$ \\
\hline Anti - HIV & $R \$ 10.00$ \\
\hline Hepatitis B Serologic Test & $\mathrm{R} \$ 18.55$ \\
\hline Hepatitis C Serologic Test & $\mathrm{R} \$ 18.55$ \\
\hline TSH & $\mathrm{R} \$ 8.96$ \\
\hline T3 & $\mathrm{R} \$ 8.71$ \\
\hline T4 & $\mathrm{R} \$ 8.76$ \\
\hline Toxoplasmosis lgG & $\mathrm{R} \$ 16.97$ \\
\hline Toxoplasmosis lgM & $\mathrm{R} \$ 18.55$ \\
\hline Rubella lgG & $\mathrm{R} \$ 17.16$ \\
\hline Rubella IgM & $\mathrm{R} \$ 17.16$ \\
\hline Fasting Glucose Test & $\mathrm{R} \$ 1.85$ \\
\hline \multicolumn{2}{|l|}{ Second Trimester Laboratory Tests } \\
\hline Oral Glucose Tolerance Test - OGTT & $R \$ 6.55$ \\
\hline \multicolumn{2}{|l|}{ Third Trimester Laboratory Tests } \\
\hline Hemogram - CBC & $\mathrm{R} \$ 4.11$ \\
\hline Hepatitis B Serologic Test & $\mathrm{R} \$ 18.55$ \\
\hline Hepatitis C Serologic Test & $\mathrm{R} \$ 18.55$ \\
\hline Toxoplasmosis lgG & $\mathrm{R} \$ 16.97$ \\
\hline Toxoplasmosis IgM & $\mathrm{R} \$ 18.55$ \\
\hline Anti-HIV & $\mathrm{R} \$ 10.00$ \\
\hline Syphilis - VDRL & $\mathrm{R} \$ 2.83$ \\
\hline TOTAL & $\mathrm{R} \$ 283.24$ \\
\hline
\end{tabular}

Source: Prepared by authors through consultation with the SUS remuneration table of September 2018 (Brazil, Ministry of Health, 2019b).

Health, 2018) for all healthy women, which includes fasting glucose tests and glucose tolerance tests, were obtained by consulting the SUS remuneration table in September 2018 (Brazil, Ministry of Health, 2019b). The values and periods of those tests are shown in Table 4 below:

It is important to note that this is an estimate of how much a low-risk pregnancy costs, but depending on each case, it can vary according to the individual conditions of the pregnant woman. Postpartum hospitalization in the maternity ward, which happens in general, for 48 hours after the delivery, maternal habits education, and health care for the newborn, has a daily puerperal fee of $R \$ 20.06$. The daily cost of a companion of the puerperal woman, within her rights, is R\$ 8.00 , values collected from the SUS price table, September 2018 (Brazil, Ministry of Health, 2019b). Considering that a woman had a full-term delivery, and the newborn has an ideal weight for its gestational age, in summary, the total costs for a healthy pregnant woman are shown in Table 3.

For costs analysis involved for prenatal care of GDM patients, research was conducted on the 493 medical records of those women under care at AAGAR-HG in 2018 (until September). The sum of all related costs was from 493 medical records, and the resulting value was the costs' arithmetic mean. The primary services observed on those records are the clinical examinations, prenatal consultations, ultrasound, obstetric hospitalization, and delivery.

In Medicine, there are protocols to be followed from the Ministry of Health, such as the minimum number of consultations, which are high-risk pregnancies, at least nine, and having a higher cost because the level of service requires a greater complexity of personnel and infrastructure. Ultrasound is performed as many times as doctors deem convenient due to the higher risk of fetal macrosomia. And thus, the various laboratory tests vary in number and quality for each patient, including daily blood glucose monitoring (hemoglycotest - HGT). Eventually, the women receive an HGT device to perform the test at home.

Hospitalizations and delivery also have different values since they require greater and better structure and obstetric and pediatric monitoring. In the sum and division of values involved in the 493 medical records, the individual arithmetic mean of $\mathrm{R} \$ 2,813.99$ was obtained for GDM patients.

\section{Discussion}

Initially, Brazil is the fourth country in the world in terms of Diabetes in adults. There are 14,3 million people aged 20 to 79 years, generating an estimated annual cost of US\$21,8 billion (IDF, 2018). According to the Pan-American Health Organization (Brazil, 2016), the prevalence of GMD varies from $1 \%$ to $37.7 \%$, with a world average of $16.2 \%$. The estimated rates of GMD in Brazil are conflicting; however, it is estimated the prevalence of GDM on SUS is 18\% (Trujillo et al., 2016).

According to Flor et al. (2015), it is estimated that almost $60 \%$ of DM cases are attributable to obesity, which causes are multifactorial and related to poor diet and bad lifestyle habits, explaining, in addition to genetic and individual issues, this variation from $1 \%$ to $37 \%$. The valuation of costs within the health area is essential, especially in the management of these costs. In accordance to Regonha et al. (2009), this valuation makes it possible to group expenses incurred for the provision of services, in addition to the valuation of each resource used (labor, materials, depreciation, etc.) and the precise definition of the cost of the service provided.

Another important application is the control and management, through monthly comparisons of costs 
incurred, which makes it possible to know the oscillations of these costs and evaluate each sector's performance. With this, the manager can use these results in decision making, such as whether to outsource a service or not, eliminate a service or keep it. Economic cost analyses are divided, in the health area, into four main methods: cost-minimization analysis, cost-utility analysis, cost-benefit analysis, and costeffectiveness analysis. These assessments seek ways to use resources efficiently and analyze the consequences or results of treatment (Cavassini et al., 2010). These evaluations can be measured by clinical, economic, or humanistic results. First, the costs of services, procedures, and treatments are calculated, and then the economic evaluations are analyzed.

\section{Cost-minimization analysis (CMA)}

The cost-minimization is the analysis made when two intervention measures have the same result but with different costs. Therefore, only costs are considered. The authors Cavassini et al. (2010) also emphasize that the costminimization: "[...] it is not a widely used analysis since it is rare to find interventions that present the same scientifically proven benefits. It is the most outstanding care taken in a minimization analysis, i.e., not to make comparisons between products with different efficacy and safety profiles that are not ethically acceptable" (p. 25).

As the comparison can only be made considering measures that have the same benefit, the cost-minimization becomes exclusive of monetary comparisons, being considered the most viable one with the lowest cost, and only this variable is evaluated. According to the Ministry of Health (Brazil, 2009): "In the cost-minimization analysis (CMA), the difference in costs between alternative interventions assumed to produce equivalent results is calculated, with these interventions differing only in the costs they incur. When two strategies have the same therapeutic efficacy and the same consequences on the patient's health but different costs, the lowest cost strategy is preferable".

A practical example of the application of this cost is found in comparing two drugs, $A$ and $B$, emphasizing that both have the same effectiveness. Drug A costs $5 \%$ more than drug B. Drug B needs one more day of observation of the patient, i.e., one more day of hospitalization, than drug A. It is necessary to calculate the cost a day of hospitalization to compare through cost-minimization, which is the most viable medication. It is important to note that cost-minimization analysis is only possible because the two drugs are equally effective at the end of treatment.

The prevention of GDM is done at UBS's primary health care level and does not involve high costs since they are related to guidance and monitoring of life habits. Prenatal consultations take place with all women, ideally a minimum of six. Such guidelines are mainly limited to weight control, diet, and physical activity. Ideally, these guidelines should preferably occur before the fetus is conceived and, if it is not possible, since the first prenatal consultation.

In this context, some women have risk factors in developing GDM, as described in Table 5. Identifying them allows maximizing the Cost-Minimization, as it is possible to direct more investment, attention, and activities to this public than the population without risk factors. It is more advantageous to invest in that population with risk factors and less in the population without risk factors, given the finite and scarce resources of the system. The monitoring of pregnant women with GDM requires a higher structural demand and is performed in tertiary health care hospitals, presenting a cost-minimization favorable to prevention.

Table 5. Average total costs comparison

\begin{tabular}{|c|c|}
\hline Average costs for healthy women & $R \$ 860.76$ \\
\hline Average costs for women with GDM & $R \$ 2,813.86$ \\
\hline
\end{tabular}

\section{Cost-benefit analysis (CBA)}

According to the Ministry of Health (Brazil, Ministry of Health, 2010), the cost-benefit analysis is considered a comprehensive analysis, contemplating all aspects of allocative efficiency. According to researchers Cavassini et al. (2010): "[...] Cost-benefit is a type of analysis in which the results are estimated in monetary values. Such analysis is not found in the literature because it is challenging to value human life and specific health conditions in financial terms" (p. 26).

The analysis focuses on evaluating the improvement provided in health and its economic cost, considering costs and expenses. For the Ministry of Health (Brazil, 2009), such analyses: "[...] are studies in which costs and benefits are calculated in monetary values, making it possible to determine whether a new technology or health intervention generates a net benefit for society. Because the value of all consequences is expressed in monetary figures, these assessments allow the comparison of health programs and interventions that produce different outcomes and health programs with other interventions outside the health area" (p. 42).

In this analysis, costs and benefits are assessed. As an example of these studies, there is the impact of implementing a face-to-face hospital care program. Analyses about the costs of implementing this program would be required, either direct (labor, consumption material, etc.) or indirect (transportation of professionals) costs and benefits acquired, such as the elimination of expenses with diseases being avoided through the program.

In addition to the need for more doctors to care for these patients, and considering the risks presented, it seems that 
more prenatal consultations, prepared nursing staff, specific physical structure, image, and laboratory tests are required. Availability of other professionals who would not be needed in low-risk prenatal care is also needed. Besides, high-risk pregnancies have higher hospitalization costs for delivery, as these pregnant women usually stay longer. Birth rates also vary compared to healthy women.

The surveyed results indicate that a healthy pregnant woman treated at the UBS, having no GDM or other complications from pregnancy diagnosis to discharge from the postpartum hospital, involves a cost of $\mathrm{R} \$ 860.76$, as shown in Table 6. The costs involved in the population with GDM, on the other hand, are 226.9\% higher, $\mathrm{R} \$ 2,813.86$, offering an advantage in Cost-Benefit when preventing the disease.

Table 6. Risk factors for GDM development

\begin{tabular}{l}
\hline Age equal or greater than 35 years \\
\hline Body mass index (BMI) $>25 \mathrm{~kg} / \mathrm{m}^{2}$ (overweight and obesity) \\
\hline Personal history of gestational diabetes \\
\hline Family history of diabetes mellitus (first-degree relatives) \\
\hline Macrosomia or polyhydramnios in a previous pregnancy \\
\hline Fetal death without apparent cause in a previous pregnancy \\
\hline Fetal malformation in a previous pregnancy \\
\hline Use of hyperglycemic drugs (corticosteroids, thiazide diuretics) \\
\hline Polycystic ovary syndrome \\
\hline Chronic arterial hypertension \\
\hline In current pregnancy: excessive weight gain \\
\hline In current pregnancy: clinical or ultrasound suspicion of excessive \\
fetal growth or polyhydramnios
\end{tabular}

Source: Prepared by authors based on the High-Risk Pregnancy Technical Manual (Brazil, Ministry of Health, 2010).

\section{Cost-utility analysis (CUA)}

Cost-utility checks explicitly the quality of life related to the patient, utilizing units of measurement of quality of life, such as, e.g., years of life extended. For the Ministry of Health (Brazil, 2009), the cost-utility analysis: "[...] is a form of costeffectiveness analysis that compares costs in monetary units and the results of a health intervention measured in terms of the duration and quality of extended life obtained through each intervention or preference for a state of health, usually for the patient" (p. 41).

The pregnant woman who will develop GDM will have to travel more often for prenatal consultations. Besides, the healthy pregnant woman's prenatal care takes place in the-neighborhood, performed at their UBS. In the case of high-risk pregnant women, prenatal consultations are held in the high-risk pregnancy clinic, which is, in most cases, in neighborhoods or cities other than those in which they live, increasing the cost-utility of prevention in the primary care, since there is a possibility of a reduction of $18 \%$ to about $1 \%$ of the total pregnancies with GDM, thus generating a higher quality of life for an essential part of the population.

\section{Cost-effectiveness analysis (CEA)}

Cost-effectiveness is used when medical interventions result in clinically similar outcomes, differing in costs and expected effects. This kind of analysis measures the cost in monetary units divided by a non-monetary or natural unit, such as "years of life saved". A health intervention is considered costeffective if the beneficial clinical result is justifiable for its cost. According to Cavassini et al. (2010): "[...] the most important is that the data are reliable and that they have received statistical treatment showing differences between different treatments. An important aspect is a distinction between efficiency and effectiveness. Efficiency is the response to the treatment obtained under ideal conditions (clinical trials) by strict control of the variables analyzed. Effectiveness is the response to the treatment in normal conditions, when interferences can modify the expected response of therapy, such as drug interactions, patient adherence to treatment, and interaction with other comorbidities. In this way, one can use 'cost-effectiveness' or 'cost-efficacy'.'.

The appropriate physical unit compares these resulting impacts from the choice of one measurement or the other. These economic intervention evaluations compare two strategies that, in this paper, will be DMG treatment and prevention. Therefore, it aims to raise the cost for preventing and treating diseases in women with GDM, comparing costs and devising better strategies for using resources.

This analysis proposes, for example, the eradication of chronic diseases in elderly patients. In this case, costeffectiveness evaluation is recommended because it evaluates benefits and costs, resulting in more objective data to support the decision making.

Thus, with adequate prevention and women awareness at the UBS level, it is possible to reduce the GDM prevalence in women. Such prevalence in Brazil is approximately 18\%, given that a large portion can be prevented with adequate preparations from medical staff and the health system, justifying the use of cost-effectiveness. Another factor that reduces the Cost-effectiveness is the complication resulted from ill-conducted monitoring of the GDM.

In accordance with the AAGAR/HG doctor, Dr. Sônia Cabrail Madi, there is a significant rate of women with GDM that lack monitoring. Since there are no data on these patients in $\mathrm{HG}$, the rate being considerable is a strong indication that the cost-effectiveness will increase with the treatment with patients with GDM compared with low-risk pregnant women. The main complications from GDM that occur in patients with lack of monitoring affecting both the mother and the fetus are spontaneous abortions, high 
blood pressure, congenital malformations (6- to 7-fold risk increases), neonatal hypoglycemia, newborn respiratory distress syndrome, fetal macrosomia, metabolic syndrome in children, type 2 diabetes mellitus (DM2) in pregnant women after childbirth.

High blood pressure can cause many other unfavorable outcomes for both the mother and the fetus since GDM has been found 2 to 4 times more frequently than the normal obstetric population (Rosen \& Miodownik 1996). Pregnant women with GDM have a $75 \%$ higher risk of having a newborn with weight, at birth, above the 90 percentile, percentage of neonatal body fat above the 90 percentile or C-peptide value in the umbilical cord above the 90 percentile, when compared with pregnant women without any of these values altered (Metzger et al., 2010).

In addition to altered fetal growth, there is an increase in the rate of fetal malformations ranging from $5 \%$ to $10 \%$, 2 to 3 times higher than that observed in the general population, and it is responsible for $40 \%$ of perinatal deaths (Almeida et al., 2003). According to Rudge et al. the negative outcome of clinical conditions of the newborn is directly related to inadequate maternal metabolic control: $52.4 \%$ of macrosomia, $14.3 \%$ of fetal death, and $8.2 \%$ of congenital malformations. Some studies indicate that the majority of women with GDM will evolve to DM2 after pregnancy, and of those, approximately $10 \%$ do so shortly after delivery, with the long-term risk reaching up to 70\% (Kin et al., 2007; Russel et al., 2006).

Complications for the pregnant woman immediately after delivery and for the fetus are greatly increased. Studies vary in relation to the increase in the population with GDM, but they converge unanimously towards a significant increase. There are also complications related to the fetus right after delivery. Studies have shown that macrosomal fetuses are at increased risk for developing obesity and DM during adolescence (Catalano et al., 2003).

When these infants reach adulthood, and because they are, in general, more obese, the women of this population, when they get pregnant will continue to account for the cost-effectiveness of lack of prevention during the period they were gestated, as this population, for having too much obesity, has a greater chance of developing DMG, among many other diseases resulting from obesity in the course of their life, generating a vicious circle. Thus, preventing DMG is an opportunity to break such a cycle.

\section{Cost-opportunity analysis (COA)}

In Economics, there is another aspect of cost analysis within the concept of scarcity: the cost-opportunity study. According to Mankiw (2013), "the opportunity cost of an item is what you give up to obtain it", i.e., when making a decision, it is necessary to be aware of the opportunity cost that accompanies that decision. Analyzing both the sub-items
"Investments in Health" and "Costs of pregnant women" in the item "Results", this analysis takes shape since there is an increasing scarcity in the potential to offer a quality health service.

Investment percentages in the health field, from the state and the municipality, increase beyond the minimum constitutionally required. It is a better rendering of resources that are being misused. As seen in the present study, there is a margin of prevention of GDM that can be manipulated if investments in this area occur. Associated with this opportunity margin, is that treatment is much more expensive in all cost analyses than prevention.

According to Barros (2007), in all decisions, medical professionals' ethical thinking in collective terms is required since a resource used in an individual is no longer available for another individual. In the public health scope, these analyses directly impact the use of resources, i.e., they directly impact investment in health. As the amount invested in health at the national, state, and municipal levels obeys the minimum percentile established by law, these analyses do not impact the value of the investment but the return that these investments have for the population's quality of life. When analyzing the potential and significant margin for reducing the prevalence of GDM from 18\% to about 1\%, there would be some interference in all costs studied here, maximizing the system.

The limitations found in this study are due to the lack of Brazilian studies that could quantify and qualify variations in the GDM incidence and its outcomes. Such lack of information caused some generalized costs, such as the division of the analysis of GDM and non-GDM patients. This comparative analysis between expenses involved in each arm by different sources can generate some bias in the sensitivity and reliability of the actual costs involved.

In high-risk pregnancies, doctors are free to request tests, in which case an analysis of all costs involved in a high-risk pregnancy service is required. However, physicians who wish to order extra-official tests besides those suggested in the protocol for low-risk pregnancies should request authorization from the municipality's Health Office, specifying why such non-routine tests are essential. The technical staff will approve or refuse it. Besides, results generated are not intended to present rigorously reliable values on the costs of preventing and treating DMG; it points to a shared path on the possibility of maximizing the health services provided to pregnant women.

\section{Conclusions}

In 2018, the city of Caxias do Sul invested approximately R\$ 254 million in the city's health, representing $27.3 \%$ of the municipality's revenues. This amount was $17.3 \%$ higher than the minimum required by law. The justification was that 
the Union's and State of Rio Grande do Sul's funding was out of date and, for this reason, the municipality needed to supplement the amount. It was not an isolated year, as it was a practice that had occurred in previous years. The state, in turn, keeps its funding above the required amounts. There seems to be a lack of strategy in municipal health management to maximize the health services provided.

The cost-benefit analysis, which measures the relationship between the monetary value of costs and benefits in terms of prevention, is seen when the average expense of a pregnant woman with GDM is $226.9 \%$ higher than the cost of a healthy pregnant woman.

Cost-minimization, which calculates the cost difference between alternative interventions assumed to produce equivalent results, is maximized when identifying pregnant women who present risk factors for developing GDM early in the primary healthcare level and invest more attention and resources for prevention in this population. A healthy pregnant woman, who had adequate care and did not develop GDM, does not need to move to the high-risk pregnancy management unit. Such centers, in general, are located far from the UBS of the neighborhoods and do not need to have a more significant number of prenatal care than those with GDM.

Also, the fetus not exposed to high serum glucose and insulin concentrations will have fewer congenital malformations, less neonatal hypoglycemia, a newborn's respiratory distress syndrome, fetal macrosomia, the chance of developing DM2, metabolic syndrome in adulthood. And the mother will have less chance of developing postpartum DM2 and other metabolic disorders. Thus, we will have a CostUtility favorable to prevention since this analysis assesses different interventions from their cost and their impact on the duration and quality of extended life obtained.

Finally, it is noted that in Brazil, about 18\% of pregnant women have GDM. The disease variation globally is from $1 \%$ to $37 \%$, showing a reasonable range of possibility to reduce GDM, since most cases can be avoided with adequate women prevention and awareness, favoring a positive balance in analyzing the cost-effectiveness generated by prevention. Analyzing values intended to health by the federal entities, there is an outdated distribution of resources applicability. More than the minimum required by law is invested in providing a minimally functioning service.

The general perception seems to be that more and more money is lacking to provide quality health care to the population. It can and should be corrected with analysis in cost studies like this that present costs of preventing and treating patients with GDM.

Therefore, there is an excellent opportunity to invest heavily in prevention, improving the quality of prenatal care and its accessibility, and increasing the training of health professionals, promoting health education broadly and democratically, and increasing the technology in monitoring pregnant women.

\section{References}

Almeida F, Leonica I, Rudge M. The biochemical nature of fetal malformations in pregnancy complicated by Diabetes. Femina. 2003;31(2):175-8

Barros P. The price of health. J Port Gastroenterol. 2007;14(4):194-8.

Bommer C, Sagalova V, Heesemann E, Manne-Goehler J, Atun R, Bärnighausen T, et al. Global Economic Burden of Diabetes in Adults: projections from 2015 to 2030. Diabetes Care. 2018;41(5):963-70.

Brazil, Federal Government. Transparency Portal. 2018. Available from: http://www.portaltransparencia.gov.br/PortalFuncoes_Detalhe. asp?Exercicio=2017\&codFuncao=10. Accessed on: June 9, 2018.

Brazil, Ministry of Health, Executive Secretariat, Secretariat of Science, Technology and Strategic Inputs. Thematic glossary: health economics. Brasília, DF: Ministério da Saúde; 2009

Brazil, Ministry of Health. Health Care Secretariat. Department of Strategic Programmatic Actions. High-risk pregnancy: technical manual. 5. ed. Brasilia: Publisher of the Ministry of Health; 2010. 302p. (Series A. Standards and Technical Manuals).

Brazil, Ministry of Health. High-risk pregnancy: technical manual. Brasília DF: Ministry of Health; 2012.

Brazil, Ministry of Health, Pan American Health Organization, Brazilian Federation of Gynecology and Obstetrics Associations, Brazilian Diabetes Society. Screening and Diagnosis of Gestational Diabetes Mellitus in Brazil. Brasília, DF: Ministry of Health; 2016.

Brazil, Ministry of Health, Pan American Health Organization, Brazilian Federation of Gynecology and Obstetrics Associations, Brazilian Diabetes Society. Screening and Diagnosis of Gestational Diabetes Mellitus in Brazil. Brasília, DF: Ministry of Health; 2017.

Brazil, Ministry of Health. Table SUS Reference September 2018. 2019a Available from: https://www.cisamusep.org.br/uploads/ credenciamento/86_Tabela_SUS_referencia-SETEMBRO_2018.pdf. Accessed on: Feb 27, 2019.

Brazil, Ministry of Health. Unified Health System (SUS): Low-risk pregnancy manual. 2018. Available from: http://bvsms.saude.gov.br/bvs/ publicacoes/pre-natal_puerperio_atencao_humanizada.pd. Accessed: Sept 27, 2018.

Brazil, Ministry of Health. Unified Health System (SUS): structure, principles and how it works. 2019b. Available from: http://portalms.saude.gov.br/ sistema-unico-de-saude. Accessed on: Feb 27, 2019.

Brazil, Presidency of the Republic. Complementary Law no 141, of January 13, 2012, Regulation of $\S 3$ of art. 198 of the Federal Constitution to provide for values on transmission according to the Union, States, Federal District and Municipalities in actions and public health services; Health Resource Transfer Rate Criteria System and the Health Expenditure Inspection, Evaluation and Control Standards in the 3 (Three) spheres of government; repeals provisions of Laws 8,080, of September 19, 1990, and 8,689, of July 27, 1993; and other measures. Brasília, DF; 2012.

Brazil, Presidency of the Republic. Law no 8,080, of September 19, 1990, definition of the conditions for the promotion, protection and recovery of health, the organization and functioning of the corresponding services and other measures. Brasilia, DF; 1990.

Catalano PM, Kirwan JP, Haugel-de Mouzon S, King J. Gestational diabetes and insulin resistance: role in short- and long-term implications for mother and fetus. J Nutr. 2003;133(5 Suppl 2):1674S-83S. 
Cavassini A, Lima S, Calderon I, Rudge M. Health assessments: calculation of costs in caring for pregnancies complicated by diabetes. Rev Admin Saúde. 2010;12(46):23-30.

Caxias do Sul. City Hall exceeds R\$ 254 million invested in health in 2018. 2019. Available from: https://caxias.rs.gov.br/noticias/2019/02/prefeituraultrapassa-254-million-invested-in-health-in-2018. Accessed on: Mar 3, 2019.

Flor L, Campos M, Oliveira A, Schramm J. Diabetes burden in Brazil: fraction attributable to overweight, obesity and overweight. Publ Health Magazine. 2015;49(29):1-11.

IDF Diabetes Atlas. 7th ed. Brussels: International Diabetes Federation. 2018. Available from: http://www.diabetesatlas.org, Accessed on: June 11, 2018.

Kin C, Berger D, Chamany S. Recurrence of gestational diabetes. A systematic review. Diabetes Care. 2007;30(1):1314-9.

Mankiw N. Introduction to the economy. 6th ed. São Paulo: Cengage Learning; 2013.

Metzger B, Gabbe S, Persson B, Buchanan T, Catalano P, Damm P. International association of diabetes and pregnancy study groups recommendations on the diagnosis and classification of hyperglycemia in pregnancy. Diabetes Care. 2010;33(3):676-82.
Regonha E, Borba V, Lisboa T, Ulhôa W. Administrative and financial management of health organizations. 1st ed. São Paulo, SP: Atlas; 2009.

Rio Grande do Sul. Message to the Legislative Assembly, Opening of the 1st Legislative Session of the 55th. Porto Alegre, RS: Legislative Assembly; 2019.

Rosen B, Miodownik M. Pregnancy and complications of type I diabetes: maternal and fetal implications. In: LeRoith D, Taylor S, Olefsky J. Diabetes Mellitus. 1st ed. 1996. p. 695-710.

Rudge M, Calderon I, Ramos M, Maestá I, Souza L, Peraçoli J. Perinatal perspective resulting from strict prenatal control in pregnancies complicated by diabetes. Braz J Gynecol Obstet. 1995;17(1):26-32.

Russel M, Phipps M, Olson C, Welch H, Carpenter M. Rates of postpartum glucose testing after gestational diabetes mellitus. Rev Obstet Ginecol. 2006;106( 6):1456-62.

Trujillo J, Vigo A, Reichelt A, Duncan B, Schmidt M. Fasting plasma glucose to prevent a complete OGTT in the diagnosis of gestational diabetes. Diabetes Res Clin Pract. 2016;105(3):322-6. 